Although the cerebral hemispheres resemble those of the carnivorous type, yet the frontal lobes are so singularly. under-developed that the author finds therein an explanation of the relative stupidity of the dolphin.

"Bidder's Organ" (Spengel) was discovered in $175^{8}$ by Rösel von Rosenhof upon the testes of Bufo calamita. Dr. Attilio Cerruti, by means of material captured in the volcanic crater of Archiagnano, near Naples, has been able to demonstrate a highly interesting cytological process which occurs in the male individuals of Bufo vulgaris during the early months of the year. Certain of the cells, named ovules, of the organ of Bidder are so strongly attracted by some of their neighbours that they actually penetrate their enveloping membranes, and their cytoplasm and nuclei flow into the invaded cells. In the majority of cases the penetration is simple, i.e. only one ovule invades a second, but multiple penetration has also been observed; and then in the case of ovules, say, $a, b, c, d$, ovule $a$ will penetrate into $b, b$ into $c, c$ into $d$, \&c. 'In all cases of penetration, degeneration ensues. Generally speaking, the invading ovule is the younger, and is one which has developed on the periphery of the organ, the invaded ovules lying nearer the centre. The author draws a suggestive comparison between this phenomenon and that of the fusion of Ascaris ova described by O. zur Strassen, which, if they develop at all, give rise to monsters.

There are also four mathematical memoirs. Signor D. de Francesco contributes a paper on the motion of a cord and on the equilibrium of a flexible but nonextensible surface (Nos. 5 and 6, 5 pp., 9 pp.), and Prof. E. Cesàro investigates the intrinsic representation of a surface (No. 7, 20 pp.) and the curve of von Koch (No. 15, I2 pp.). A lengthy contribution to the theory of ternary biquadratic form and its resolution into factors (No. 13, I02 pp.) is by the hand of Ernesto Pascal.

R. T. G.

PHYSIOLOGICAL ECONOMY IN NUTRITION.

$\mathrm{NE}$ of the most remarkable points in the recent history of physiological research is the small amount of attention bestowed upon the important question of nitrogenous metabolism until within the last few years. The older work of Voit and of Pflüger has for long been regarded as authoritative, in spite of the fact that these two observers are not at one on many essential facts. They, however, agree that proteid food is a most essential constituent of our diet, and that a minimum allowance per diem of about roo grams, corresponding to 16 to 18 grams of nitrogen, is necessary for the well-being and equilibrium of the average adult human individual. A dietary containing this amount of proteid or albuminous material would not be regarded by the average meat-eating Englishman to be a very liberal one, and is frequently exceeded.

So firmly rooted has this idea of a proteid minimum intake of roo grams become that not only is it stated as an axiom in the majority of text-books, but it forms the basis of dietaries prescribed by responsible Governments for use on military service, \&c. The doctrine that proteid food is the most necessary of all foods is so thoroughly ingrained, even upon the lay public, that in popular parlance the words nutritious and nitrogenous are almost synonymous. This is a very dangerous mistake, for the non-nitrogenous constituents of diet, the carbohydrates and the fats, are equally necessary for the maintenance of bodily heat and energy, and so are equally, though in a somewhat different sense, to be regarded as nutritious. An example of this erroneous way of regarding food is to be seen in advertisements that meet the eye everywhere preparations of milk, for instance, are sold which contain mainly the proteid matter of that fluid, and are vaunted as containing all the nutritious elements, the other constituents being looked upon as useless. As a matter of fact, milk is of special value on account of the admixture of the non-proteid with proteid material. in the concentration camps which were established during the later phases of the South African War, such hardships as occurred there were mainly due, not to lack of proteid nutriment, for the standard of nitrogen was fully maintained, but to lack or scarcity of vegetables and other sources of carbohydrate food.
For some considerable time, certain experimenters in Germany have striven to demolish the fetish of the irreduicible minimum of the 16 or 18 daily grams of nitrogen, but their work has not attracted world-wide acknowledgment; the experiments they recorded were either made for too short a time or on too few people to be regarded as epoch-making.

It has been left to America to make the question one of immediate and urgent attention, and I propose in this article to bring the conclusions of these American investigators before the readers of NATURE.

Prof. R. H. Chittenden, of Yale University, and Dr. Otto Folin, of Waverley, Massachusetts, are the two principal exponents of the new doctrine, and I propose to deal with them in that order.

\section{The Work of Chittenden.}

Chittenden has been working at the subject for some years, and the results of his labours are given in a volume which will amply repay perusal entitled "Physiological Economy in Nutrition" (New York: F. A. Stokes Co., 1904). A more popular exposition of his ideas has been published in a recent number of the Century Illustrated Monthly Magazine (October, 1905, p. 859 et seq.).

The question was first brought to the notice of Prof. Chittenden by Mr. Horace Fletcher, who states that he cured himself of dyspeptic troubles by lessening his proteid nutriment below what was regarded as the physiological standard. $\mathrm{He}$ has started a propaganda on the subject from the economic point of view, for proteid is the most expensive of the articles of diet. One at once sees that the question is not merely one for the student of science, but is most important for the man in the street as well. Owing, no doubt, to his lack of physiological knowledge, Mr. Fletcher attributed the benefits he derived to a thorough mastication of the comparatively small amount of food he took. Mastication is, of course, of importance, but it does not possess the superlative importance attributed to it by $\mathrm{Mr}$. Fletcher, and will not explain the results of the experiments made by Chittenden and his fellowworkers.

The number to which I have already alluded ( 16 to 18 grams of nitrogen a day) is based roughly on the usual diet of the meat-eating nations, and it is argued that habit and instinct alike are safe guides in determining such a number, and the effects of such a diet in the maintenance of health and bodily equilibrium have been abundantly proved through centuries of experience. It forms, as already stated, the basis of the usually accepted dietaries of Ranke and of Voit.

In other nationalities, it is true, a different figure has been arrived at, and the same argument of habit and experience might equally well be used in its favour. Thus in certain semi-civilised races the proportion of flesh food is much larger, and in other races, again-and this is the commoner variation - the proteid intake is less. We need, however, only consider the second alternative, for one can hardly suppose anyone will advocate a return to more carnivorous habits. It is alleged that in such nationalities as the Japanese, or in groups of people like vegetarians, and in certain rural populations, health and equilibrium are as well maintained as in the ordinary meat-eating inhabitants of our large cities. Those who hold that the number 16 to 18 is the correct one have explained the different number arrived at by the nations of the Far East as a racial difference propagated by long centuries of inheritance, or have tried, more or less successfully, to show that such people come nearer to Voit's standard than had been supposed, or else that they are not properly nourished.

Such explanations will not hold water when applied to the experiments conducted by Prof. Chittenden upon himself, his colleagues, his students, and upon a considerable number of athletes and soldiers. These experiments lasted in all cases for months, and in some for more than a year. The proteid intake was reduced to half, and in some cases to less than half the number hitherto regarded as normal. After a variable initial drop in body-weight, the deprivation was apparently followed by no untoward results. Equilibrium was maintained; the health remained 
perfect or improved; the muscular power of athletes was increased; mental acuity was undiminished; and desire of richer food disappeared.

Chittenden argues from such results (and daily observations were diligently maintained throughout each experiment) that his scanty proteid diet is the normal, and that the average meat-eater is the man who is abnormal. ne says :- "When we recollect that these eighteen grams or more of nitrogen in the urine reach the final stage of urea, \&c., only by passing through a series of stages each one of which means the using up of a certain amount of energy to say nothing of the energy made use of in digestion, absorption, \&c., we can easily picture to ourselves the amount of physiological labour which the daily handling by the body of such amounts of proteid food entails. It needs very little imagination to see that a large amount of energy is used up in passing on these nitrogenous waste products from organ to organ or from tissue to tissue, on the way to elimination, and we can fancy that liver and kidneys must at times rebel at the excessive labour they are called upon to perform." He then goes on to point out that many of these waste products, like uric acid, are toxic, and the evil results that ensue from their accumulation.

It is on such grounds that Chittenden advocates a revolution in our ordinary dietary, and his arguments for temperance in proteid intake are entitled to careful attention. He is no crank or faddist, and his cunclusions have been arrived at by the true scientific method, that of experiment.

There will be many who will pay no attention to them at all. The bon vivant, for instance, will resent any interference with his habits, gout and other evils notwithstanding; and certainly some of the meals Chittenden describes do not appear very appetising; for instance, a banana and a cup of coffee for breakfast; bean soup, bread ( 1 oz.), bacon ( $\left.\frac{1}{5} \mathrm{oz}.\right)$, fried potato, salad, prunes, and another banana for supper. But no doubt variations in the way in which the nutriment can be obtained are possible of introduction.

The honest inquirer after truth may also have his doubts, and it cannot be disputed that there are difficulties, and serious ones, which will have to be answered before the advocacy of the new idea will meet with success.

One would like to know, for instance, whether the numerous subjects of the experiments are still keeping up their reduced diet, or whether they have returned to the flesh-pots after a period of enforced abstinence. If they are still maintaining their new habits, one would like to know how they fare in a few years' time, if they have the reserve force to enable them to withstand a severe disease, great fatigue, or privation during a siege, and whether the initial briskness they felt when they dropped their large (probably too large) proteid intake is maintained, or whether, on the other hand, they present the appearance and symptoms of underfed persons.

A cautious and conservative person would point to the danger of a sudden change in the habits of years and generations, even though it may ultimately be necessary. Most physiologists will recall the analogy of metabolic changes to commercial undertakings which they employ when presenting balance-sheets of intake and output in the body, and say, just as in a business enterprise, a large turnover implies healthy activity, so in the body a frequent exchange of the old for the new is within certain limits an indication of vigour, and a necessary accompaniment of healthy action. The liver, the function of which it is to turn nitrogenous metabolites, which may be harmful, into urea, which is harmless and easily disposed of is adequately large and active in health to deal with considerable quantities of material.

Then we may point to the stunted and feeble inhabitants among the poor and ask why they are so. Unhealthy dwellings, excess of alcohol, insufficiency of light and pure air will explain a good deal of their condition; but is it not underfeeding, especially in early life, which is at the root of the matter? They have had nolens volens to subsist on a diet very like Chittenden's, but their nutritive condition is not such as to make people who can afford a mcre liberal table inclined to follow their example.

Further, one may inquire, why is it that, with a few NO. I 892 , VOL. 73$]$ exceptions, the meat-eating nations have risen to the front? and why is it that in countries like India, where the native population is diluted with the white races, it is the former who are more readily attacked by disease, and more easily succumb to its effects?

A question intimately related to that of a suitable diet for the healthy adult is that of the feeding of children. The diet of the growing infant is relatively far richer in proteid than that of the adult. Must we also reduce the intake of proteid food in the child? This is a question that Chittenden has not touched, but clinical experience does not point, so far as I can ascertain, to an affirmative answer, either with regard to the feeding of infants or of certain classes of invalids.

These questions and difficulties cannot be answered offhand. There is a wide field still open to investigators, and not until such difficulties are removed will it be possible for physiologists to state that Prof. Chittenden has convincea them.

\section{The Work of Folin.}

Whether Dr. Otto Folin has seen these difficulties or not, he certainly does not mention them, and he appears as an advocate of the new doctrine, not only from a study of Chittenden's investigations, but also as a result of his own researches. Nitrogen enters the body in the complex compounds known as proteids; it leaves the body mainly by the urine in the shape of certain simpler substances of which urea is the most abundant. Folin has approached the subject from the aspect of nitrogenous discharge, and has published his investigations on the urine in a series of three interesting papers in the American Journal of Physiology (vol, xiii., 1905, pp. 45-65, 66-115, 117-138). Although it is possible that some of his conclusions may not stand the test of time, all of them are most suggestive; and his theory of proteid-metabolism will stand out as one of the most important contributions to physiological literature that has appeared within recent times.

The question, what is a normal diet? is intimately bound up with another, and that is, what is a normal urine? The text-book statements on the composition of this fluid are all derived from the examination of the urine of people accustomed to the Voit dietary; but if the diet of the future is to contain only half as much proteid, the urine of the future will naturally show a nitrogenous output of half that which is now regarded as normal. In people on such reduced diets, Folin shows that the decrease in urinary nitrogen falls mainly on the urea fraction, and in some cases the urea accounted for only 66 per cent. of the total nitrogen eliminated. The other nitrogenous waste products alter but little in absolute amount, but relatively their amount rises; in particular, the creatinine remains remarkably constant in absolute amount in spite of the great reduction in the proteid ingested. He goes on to point out that the laws governing the composition of urine are the effect of more fundamental laws governing proteid katabolism. Voit's well known theory on this question states that katabolism, i.e. the breaking down stage, occurs only in "circulating proteid"; the small amount of "living proteid" which dies is dissolved, and is then added to the "circulating proteid," where the final breakdown into waste products takes place. Pflüger, on the other hand, believes that all proteid taken in as food is first assimilated and becomes a corporate part of living cells before it undergoes the katabolic change. This view has met with more general acceptance than Voit's. The opinion held by Folin is that neither of these extreme views is correct, but that nitrogenous katabolism is of two kinds: one is inconstant and immediate, varies with the food, and leads to formation of urea and inorganic sulphates, but not of creatinine and " neutral sulphur." The other is smaller in amount, constant in quantity, and is largely represented by creatinine, " neutral sulphur," and to a less extent by uric acid and ethereal sulphates. This latter form of metabolism, representing the breakdown of actual living substance, may be termed tissue or endogenous metabolism, whilst the other is exogenous. Exogenous metabolism therefore represents an immediate discharge of the nitrogenous constituent of proteid matter, leaving the non-nitrogenous moiety available for use in heat and energy production, fulfilling, in other words, the same func- 
tion as carbohydrate and fat. Endogenous metabolism sets a limit to the lowest level of nitrogenous equilibrium attainable, and the proteid necessary to balance this part of the nitrogenous waste is indispensable for the repair of the tissues. Whether the amount exogenously katabolised can be entirely dispensed with is at present questionable. I fancy most physiologists would agree that it cannot with safety be wholly dispensed with; the body would then be working too dangerously near the margin, and in any case where an excess of nitrogenous waste is necessary the call would have then to be made on the tissue proteids.

Recent researches on digestion of proteids in the alimentary canal have shown that they are largely broken down into simple substances like ammonia, leucine, tyrosine, and other amino-acids. This is regarded by Folin as a preliminary means of getting rid of the excess of proteid matter usually ingested; these waste products, according to this view, are taken to the liver, rapidly transformed into urea, and so got rid of. The evidence that they are synthesised by the cells of the body into "living proteid" is regarded by him as inconclusive and largely teleological. An extensive formation of Voit's " circulating proteid," to be followed immediately by decomposition into urea, is quite as improbable as the corresponding formation and decomposition of Pflüger's organised protoplasm. The organism requires in its food only the small amount of nitrogen necessary for endogenous metabolism; the nitrogen of the extra proteid is unnecessary, and the organism has at hand an active mechanism for casting it out.

To attempt to summarise all the points of detail into which Folin enters is beyond the scope of this article: all I desire to do is to bring forward the main principle of the new idea. There is, however, one further point of sufficient importance to warrant specific mention, and that is the one related to muscular work. The fact that muscular work does not increase proteid katabolism may be accepted as an approximate truth; it is not absolutely true; there is a certain increase of nitrogenous waste, but it is insignificant as compared with the enormous and immediate increase of waste carbonaceous products like carbon dioxide that are discharged when muscles are thrown into action.

If current views on the nature of proteid katabolism are correct, this fact is very difficult to explain, but it becomes intelligible if proteid katabolism, in so far as its nitrogen is concerned, is independent of the oxidations which give rise to heat or to the energy which is converted into work. "Whether severe work will have an effect on the endogenous metabolism cannot be shown by investigating urea excretion; determinations of creatinine and "neutral sulphur" are necessary for a study of that question" (Folin).

One of the benefits such papers as those of Folin confer is that new ideas of this kind suggest fresh work to others, and it can hardly be doubted that in the future physiological literature will contain many papers criticising and supplementing the theories and facts which Folin has brought forward. Already one of these has appeared in the current issue of the Journal of Physiology (Noël Paton, vol. xxxiii., p. I, 1905). In this Dr. Noël Paton on the whole agrees with Folin concerning the dual nature of proteid metabolism. He, however, differs from him in certain points of detail. He finds in the dog, for instance, that creatinine excretion is not so constant a quantity as in man. $\mathrm{He}$ also doubts whether it is possible to draw any hard and fast line between endogenous and exogenous metabolism, and that urea may be a final product of both. He explains some of Folin's results by variations in the activity of the liver, for it is in this organ that ammonia compounds and the like are transformed into urea. A study of various diets upon the flow of bile (which may be taken as an index of hepatic activity) shows that proteid diet specially stimulates the metabolic processes in the liver. Hence on a diet which is poor in proteid the hepatic action may be sluggish, and will therefore fail to convert a large quantity of waste nitrogen into urea, while on a diet rich in proteid the conversion must be much more complete. As with the nitrogen, so with the sulphur, the amount of which is completely oxidised must be determined by the activity of the changes in the liver.

Such, then, is a brief summary of some of the recent NO. I892, voL. 737 work in connection with these most important problems. We can hardly doubt that the steps made are in the direction of progress of knowledge, but it is as yet too early to prophesy where they will ultimately lead us.

\section{W. D. H.}

\section{PHOTOGRAPHY IN NATURAL COLOURS.}

$A^{N}$ exhibition of photographs in which the aim of the photographer has been to imitate the colours of the objects represented is now open at the offices of the British Journal of Photography, 24 Wellington Street, Strand, and will remain open until the beginning of March. The specimens are all direct photographs in the sense that they have been produced by photographic printing, and not in printing presses from blocks or plates. The editors of the British Journal of Photography must be congratulated in that they have succeeded in bringing together a more representative collection than has ever been on view before.

The first glance that one instinctively takes round a room immediately on entering it produces a feeling quite different from that experienced on giving a momentary and general look round in a small gallery of paintings. In the latter case there is an impression of completeness in the work that gives satisfaction, whether or not this is maintained when the pictures are more carefully examined; but here there is a sense of a want of finish, an impression of experiment or incompleteness, as if those who made the pictures had left off before they had got the effect they sought to get. Perhaps others will not experience the same feeling, but it was very marked in the case of the writer, and, so far as the origin of it could be traced, it appeared to be due to a general crudeness of colour, or the predominance of one certain colour over the whole picture, or an indecision of outline that was evidently not intentional. Some examples suffer in one way and some in another; a few are quite satisfying, and must be very excellent if not perfect, but they are not in a sufficient proportion to affect the general impression.

It will hardly require technical knowledge to convince the visitor that the personality of the photographer has a great deal to do with the result. The more skilful the worker the better the photograph, that is, the more true are the colours and the fewer the errors of manipulation in all ways. As the skill of the worker has so much to do with the result, it is impossible to decide as to the merits of the various methods. Strictly speaking, it is not possible to determine the value of any of the photographs, for in no case is the original put by the side of it. Who would ever dream of attempting to judge the merits of a copy except by comparing it with the thing copied? Yet the writer has never seen or heard of a demonstration of the possibilities of a method of colour photography by an exhibition of a coloured object and its photograph side by side.

The effect of the personal element, or, in other words, the varying skill (or perhaps the varying luck) of different workers, is very clearly shown in the examples of the same process by different persons, or where an optically inferior method gives a better result. As an example of this last we would refer to Nos. I2 and 33, both apparently from the same group of fruit, \&.c., and both made of three superimposed films. In No. 33 the films are not cemented together, yet this picture is brighter than the other.

The only example of the immediate production of the colour of the incident light, and in this case the colour is not pigmentary but due to interference and visible only at a certain angle, is a very successful spectrum by the Lippmann process contributed by Mr. E. Senior. With two or three exceptions, the rest of the exhibits are three-colour prints. The fundamental principles are the same in all. Three-colour records are made by photographing the object through coloured media, getting the red, green, and blue of the object separately recorded. From these three negatives suitably coloured prints are made and brought together. In the Joly process, two specimens of which are lent by Mr. E. J. Wall, the three colours are arranged in series of fine parallel lines, and it is necessary to get so far away that these lines are indistinguishable, otherwise they are annoying to the spectator. The starch-grain method of 